\title{
$\mathrm{PH} 9 \mathbf{1}_{\text {panorama }}$
}

\section{Muertos revividos: motor para el desarrollo económico, cultural y turístico}

El año 1997 marca en Aragón una nueva era o, más bien, la era de la recreación histórica entendida como tal. Es cuando surgen Las bodas de Isabel de Segura: cuatro días en los que, en tiempo real y sobre escenarios naturales, la ciudad recrea el desenlace de la leyenda histórica de los amantes de Teruel. La proliferación de eventos semejantes plantea varias cuestiones al recreacionismo: ¿qué?, ¿cómo?, ¿quién?, y sobre todo ¿para qué? Desde hace seis años la Fundación Bodas de Isabel asume la responsabilidad de poner un poco orden en el sector.

Raquel E. Esteban Martin | Fundación Bodas de Isabel

URL de la contribución <www.iaph.es/revistaph/index.php/revistaph/article/view/3907>

\section{Recuperar la figuras históricas para conservar el patrimonio local}

Desde personajes iberos y romanos hasta el mismísimo san Jorge, pasando por el Cid campeador, Abén-Razín, Ramiro II, Alfonso II, Jaime I, Isabel de Segura, Diego de Marcilla, Martín, Fernando (el de otra Isabel), la Dolores o Agustina (la de Aragón)... las postrimerías del siglo XX se vieron sorprendidas por un torbellino de reyes, plebeyos, moros y cristianos campeadores, batalladores, castos, humanos o conquistadores. Figuras que conmocionaron el territorio recuperando (con mayor o menor acierto) un patrimonio dormido, piedra angular para reivindicar la identidad de un pueblo.

El año 1997 marca en Aragón una nueva era o, más bien, la era de la recreación histórica entendida como tal. Es cuando surgen Las bodas de Isabel de Segura: cuatro días en los que, en tiempo real y sobre escenarios naturales, la ciudad recrea el desenlace de la leyenda histórica de los amantes de Teruel.

\section{La receta}

La fórmula ideada para este evento combina el rigor histórico con la capacidad para divulgar la historia, los modos, personajes y vida cotidiana de una villa de frontera en el año 1217. Es capaz de crear un nuevo tejido social y de estructurar la participación de cientos de personas y asociaciones en un marco coherente, que ha conseguido mantenerse, consolidarse y crecer en el tiempo.

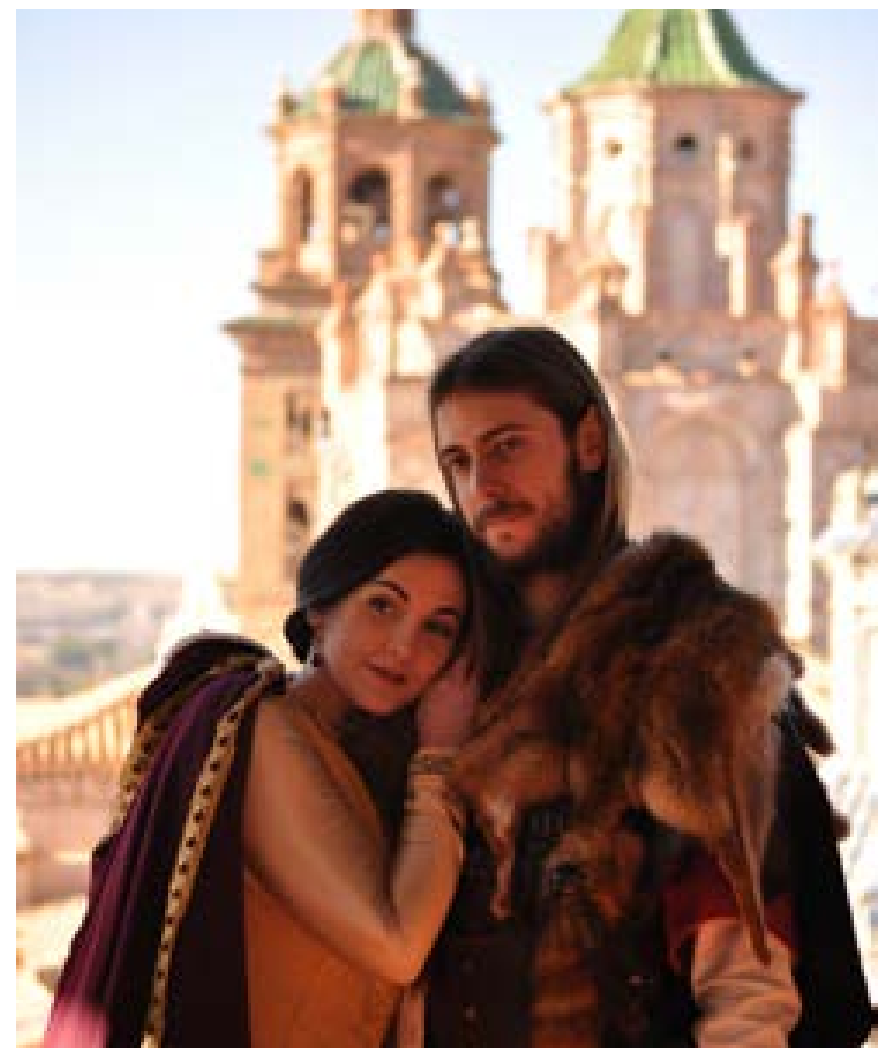

Isabel y Diego. 2017 | foto Fundación Bodas de Isabel

En la edición de 2017 han participado 150 actores (sonorizados y con textos), 5.000 personas vestidas según su personalidad de época agrupados en casi 200 grupos independientes y alrededor de 17.000 personas vestidas al modo del siglo XIII hispano. 
Evidentemente, el revulsivo social, cultural, turístico, y su impacto económico demostrado ha ido haciendo que muchos otros sigan su estela y se afanen en recrear, aunque no siempre se acierte a equilibrar la cantidad con la calidad.

El resultado de la proliferación de iniciativas es un contexto variado y confuso donde, si muchos se suben al carro sin conocer las claves que hacen de la voluntad un evento de éxito, otros juzgan injustamente determinadas manifestaciones por su supuesta carencia de rigor o por la utilización de lenguajes escénicos, inexistentes en la época recreada, pero necesarios para llegar al público, al espectador actual.

Así, desde la Fundación Bodas de Isabel asumimos la responsabilidad de poner un poco de luz y orden en el sector. Para ello llevamos 6 años organizando (principios de octubre) un congreso internacional donde, además de plantearse un tema transversal afín a los contenidos y repertorio de muchas épocas, y de reivindicar las manifestaciones históricas como uno de los motores de impacto y desarrollo económico, hemos puesto todo el empeño en lograr las definiciones semánticas apropiadas para referirnos a lo que se está haciendo, ayudar a comprenderlo, evitar juicios de valor y mejorar su calidad.

\section{Estudios de impacto}

En esta línea, la Dirección General de Turismo del Gobierno de Aragón ha encargado a la Fundación Bodas de Isabel el estudio de un producto turístico que analice y promocione el territorio y su patrimonio desde el interesante crisol de manifestaciones históricas que tienen lugar en esta comunidad autónoma: reconstrucciones, recreaciones, conmemoraciones, celebraciones...

Así, un mapa calendario de las manifestaciones históricas en Aragón permitiría presentar al turista un paquete de ofertas muy interesante.

Las manifestaciones históricas, además de recuperar el patrimonio, acercan a propios y visitantes la experiencia de lo humano y sus producciones a través de la historia (arte, gastronomía, música, danza, paisajes...).
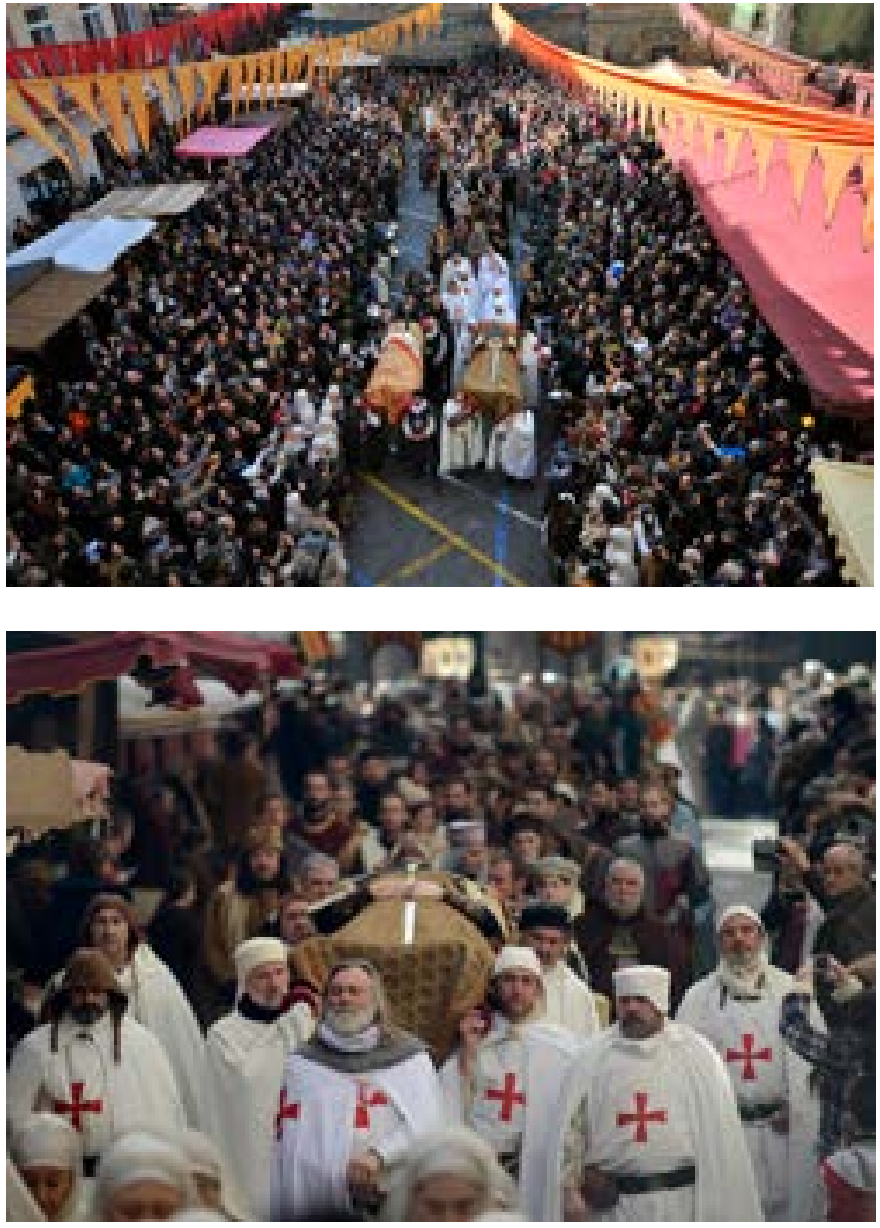

Templarios con Diego, en la calle San Juan de Teruel. XX Bodas de Isabel, 2016 | foto diegoandlori.com

Tal y como afirman algunos de los gurús de la economía americana, en estos tiempos de crisis, son los clusters creativos que aparecen en localidades urbanas de tamaño medio, uno de los primeros motores de activación e impacto económico.

Las manifestaciones históricas se articulan generalmente desde este tipo de agrupaciones humanas formateadas como asociaciones, fundaciones, empresas con mayor o menor apoyo institucional. Por lo tanto hay que tenerlos muy en cuenta para posicionar una localidad, su personalidad y su valor patrimonial. 